\title{
"Ofrendas del tiempo" de Leonel Calderón Acuña'
}

Por Alejandro Serrano Caldera ${ }^{2}$

Recibido: 19 de enero de 2014 / Aprobado: 28 de marzo de 2014

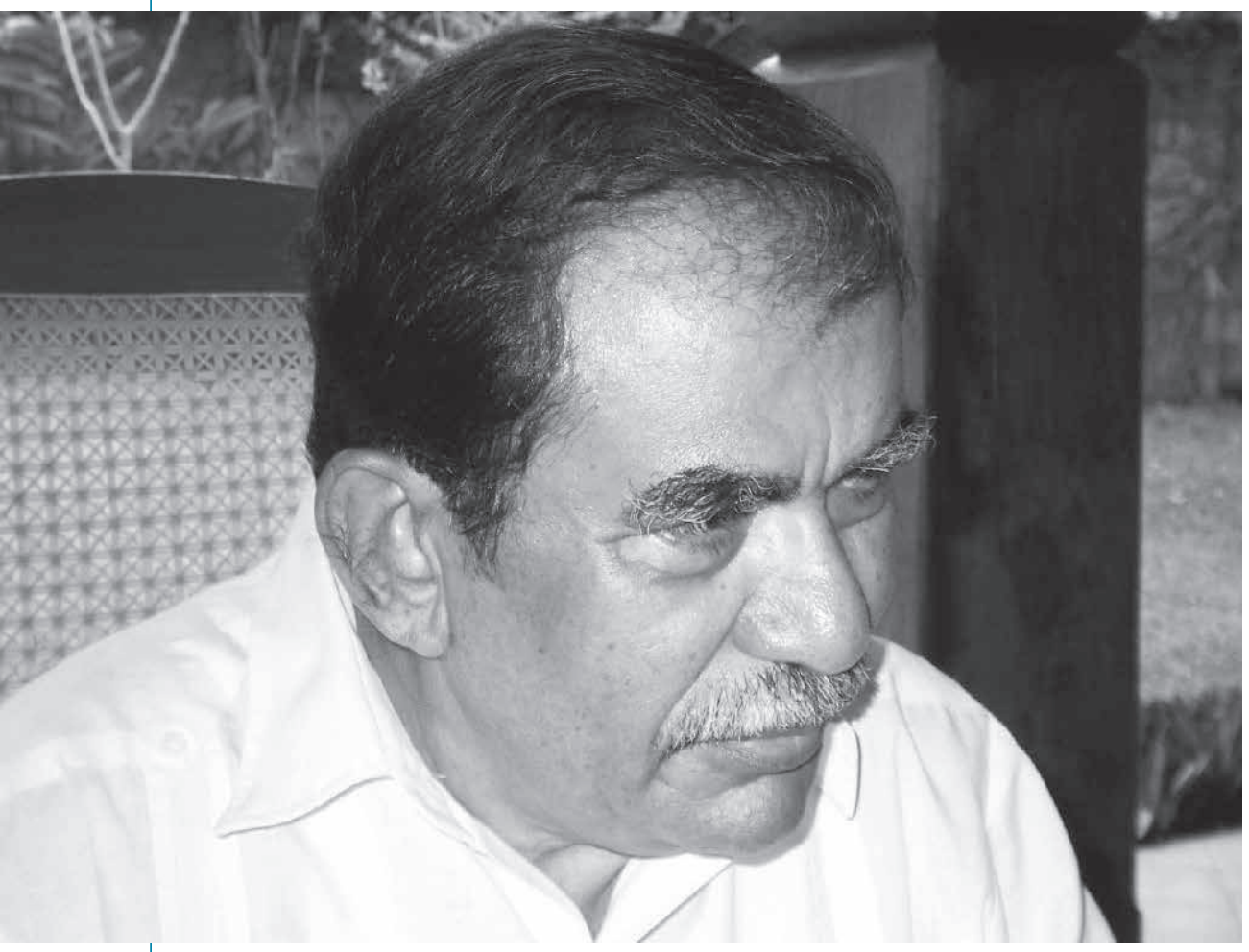

E 1 libro de Leonel Calderón, Ofrendas del Tiempo, es una reflexión metafísica expresada en la estética de sus versos. En él se realiza aquella afirmación de Husserl según la cual "filosofía y poesía, en su origen más íntimo, están entrelazadas y poseen un parentesco secreto en el alma."

Leonel en su libro nos conduce por los caminos de la angustia del ser en los que descubre la convergencia ontológica de ambos: la angustia es una forma del ser y el ser encarna en la angustia. Es quizás el sentido inicial de su libro, esa primera parte que él denomina "banal y cotidiana", a partir

\section{RESUMEN}

El filósofo Alejandro Serrano Caldera, sobre la obra poética "Ofrendas del Tiempo" de Leonel Calderón Acuña, señala que transcurre entre la angustia existencial y la experiencia metafísica como diálogo que surge de la raíz misma del ser y se dirige a un horizonte infinito de fe y esperanza.

Palabras clave: Hombre, tiempo, fe, esperanza.

\section{ABSTRACT}

Alejandro Serrano Caldera, philosopher, points out about poetic work: "Offerings of the time" by Leonel Calderon Acuña, that it passes as a dialog between the existential anguish and the metaphysical experience, which arises from the origin of being and is directed to a infinite horizon of faith and hope.

Key words: Man, Time, faith, hope.

1 Poeta nicaragüense

2 Filósofo y politólogo nicaragüense. 


\section{Literatura}

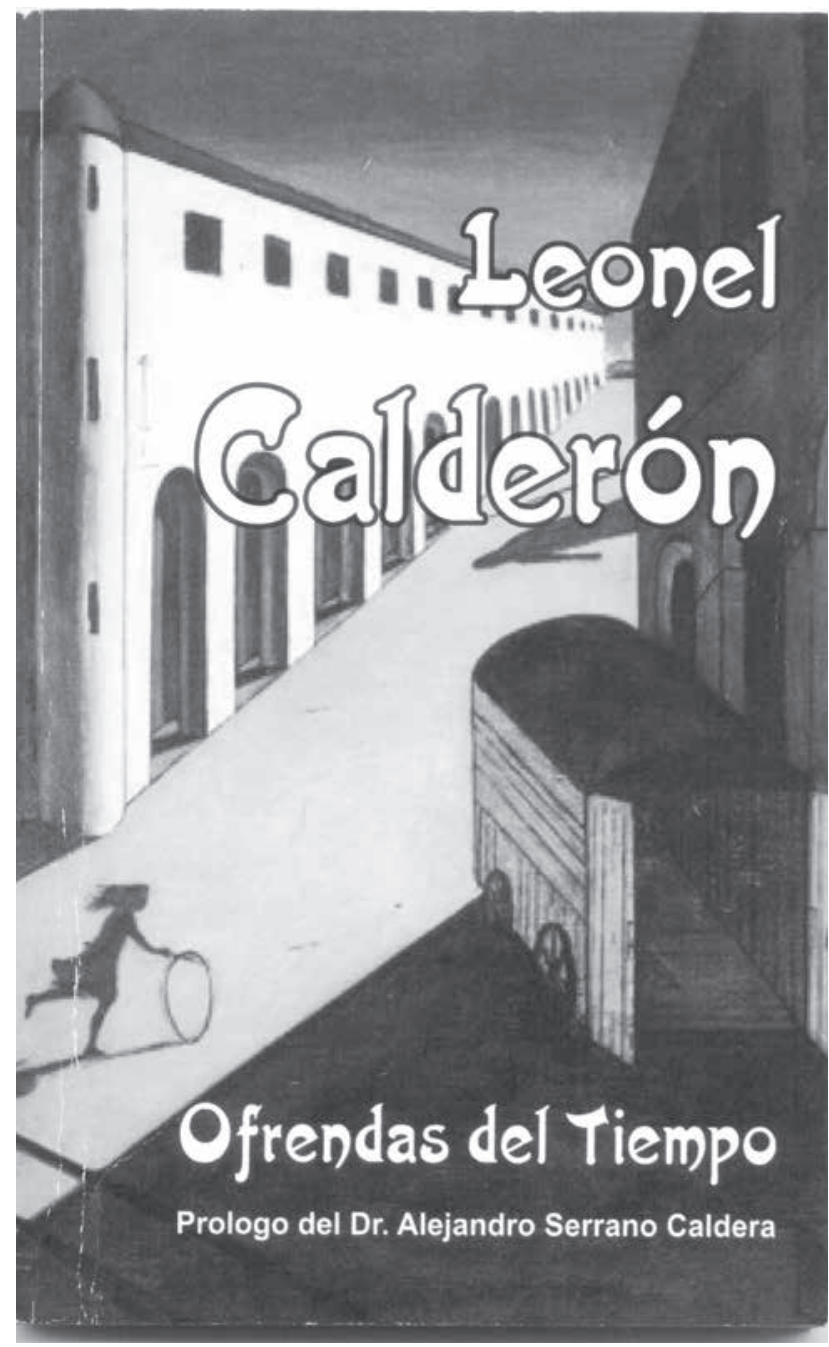

de la cual su poesía nos conduce a la expresión del ser, a las soledades en las que el tiempo es la condición universal en que reside, vive y muere el ser, que es en sí mismo tiempo que pasa por él, o más preciso aún, y siguiendo la idea que alguna vez expresó Fernando Gordillo, ser que pasa por el tiempo, pues el ser pasa en su corta y fugaz existencia por el tiempo, mientras el tiempo permanece. Ya Platón en Timeo decía que "el tiempo es la imagen móvil de la eternidad", ese fragmento que le es dado a conocer y vivir al ser.

La angustia existencial de la poesía de Leonel Calderón se presenta a través del diálogo consigo mismo, de las preguntas que interrogan, “¿de quién es ese largo alarido, ese grito perdido en la noche?", "¿de quién es esa sed de infinito?” , “qquién es ese peregrino que no llega jamás a su tierra?", y la respuesta seca y categórica proclama, "es el hombre". Es el hombre "perdido y en crisis perpetua" ... "sombra insonme que pasa de prisa, hoja muerta que arrastran los vientos".

Peros esas efímeras huellas borradas en la arena, esos sueños que murieron a mitad del camino, encuentran más allá de todo la eternidad de Dios, la fe por la que cree con toda certeza que es "un ser para la eternidad".

De esa forma su libro transcurre entre la angustia existencial y la esperanza metafísica. Las tres partes en las que está dividido, "Banal y cotidiano", "Soledades", y "Corta y fugaz existencia", son un diálogo que surge de la raíz misma del ser y se dirige al horizonte infinito de fe y esperanza. Para ello demanda implacable en los últimos poemas del libro, despojarse de las penas que torturas, guardar los recuerdos más lóbregos en un viejo cofre, y en ese mismo sentido, exige que se alejen sus estrellas quebradas y que se hundan sus agónicas lámparas.

El tema de la angustia y más aún la posibilidad de trascenderla se reafirma en su poema dedicado al gran teólogo y filósofo Soren Kierkegaard, que brilla desde su inmensa soledad enseña que el ser humano no es abstracción racional, sino "hondo sentimiento, verdad para sí y vida y dolor sin igual". Por ello, "a Dios no se busca con la pura razón. Es intimidad, muy honda experiencia... es algo vivido en la propia existencia". Y así, de esa forma, el poema de Calderón a Kierkegaard transita de la angustia, la soledad y el dolor, " a la luz eterna del Divino Cristo".

El libro es poesía filosófica y filosofía poética, búsqueda de la raíz y el destino de la existencia humana a través de la estética y el arte. Ofrendas del Tiempo es la ofrenda del ser humano al tiempo en la transitoriedad de la existencia, pero, sobre todo, es la ofrenda del tiempo al ser humano en la posibilidad de alcanzar, a pesar de la angustia, la eternidad en el instante de la esperanza y de la fe.

Abril, 2012 


\section{Literatura}

\section{Selección de poemas de "Ofrendas del Tiempo"}

\section{Soledades}

A mis amigos Dr. Chester Zelaya $V$.

y señora Lic. Lisbeth González

magnificos lectores de la sublime poesía

Soledad de las piedras oscuras

asidas con sus hiedras y musgos

al tiempo que no se detiene;

iah! el tiempo que deja su huella

en el hombre, en el bruto, en la piedra, en el árbol.

2

Soledad la del árbol

en medio del llano baldío;

se caen sus hojas ya mustias

se secan sus ramas,

se pudre y se ahueca su tronco

antaño muy verde y fornido

ya no tiene flores ni dulces racimos

está seco... está solo.

3

Soledad la del mar

que fiero se agita,

del mar que en sus olas

danza azul y sonoro

su baile de ensueño y arena;

soledad de sus profundas,

de sus lóbregas costas nocturnas,

de su espuma regada en la playa

de sus conchas hermosas, muy blancas

de sus peces que mueren.

4

Soledad, la del viento que no tiene sosiego,

y corre veloz de un lado hacia otro

y gime doliente en los sauces

y canta en los pinos altivos

y se escucha en la noche su ronco bramido

que derriba violento los árboles.
5

Soledad de la luna que cuelga del cielo

y del sol que muy rojo se muere a lo lejos, de las blancas estrellas lejanas ...

Soledad cuando el hombre contempla en la noche

y le aterra muy hondo el Espacio infinito.

Sábado 10 de octubre, 2009

\section{A veces es trágico}

A veces es trágico tener clara conciencia que llevas un comienzo y que tienes un fin y que cargas de siempre con pesada existencia donde la vida exprime y agita su trajín.

Cada día que avanza uno menos que tienes y un crepúsculo ido, es día que no vuelve y en banales objetos tu vida se entretiene mientras la helada noche ya te abraza y te envuelve.

Si en pantanos caminas y sigue un laberinto si en estériles tierras va quedando tu huella pide a Dios que muy pronto todo sea distinto y se encienda en tu alma el fulgor de una estrella.

Lunes 17 de mayo, 2010

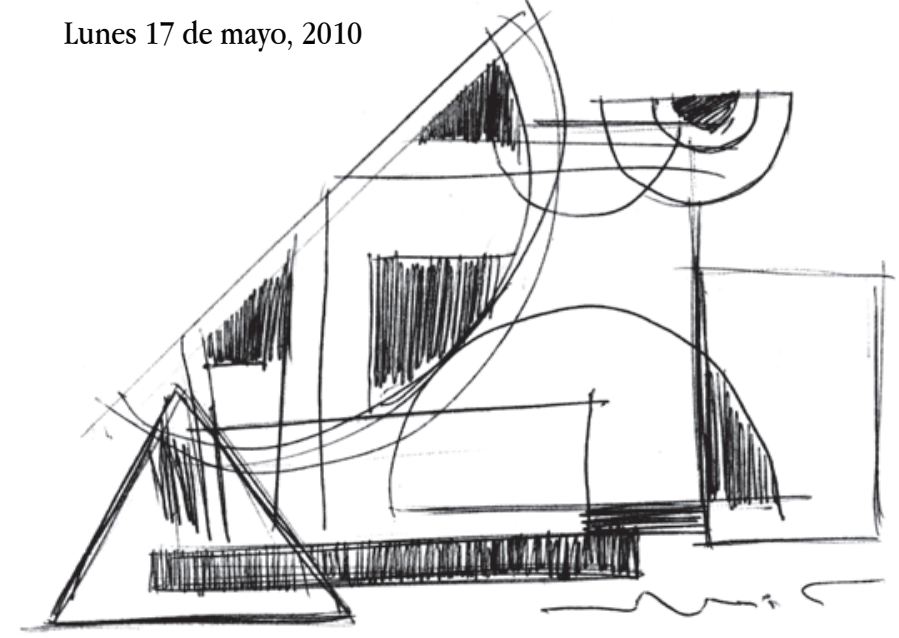

Autor: Arnolkis Turro 


\section{Literatura}

\section{Así llegó}

A la memoria de Eduardo Báez Cruz

Amigo y hermano en el arte.

Así llegó la muerte en puntillas, y con el dedo índice tocándose los labios.

No sonó su esqueleto ni enseñó su guadaña; llegó no más,

llegó de pronto

y sin pedir permiso a nadie

se llevó presurosa

al sorprendido soñador.

Domingo 09 de mayo, 2010.

\section{De profundis}

A mis entrañables amigos

Lic. Rolando José Pérez García y

Lic. Carmen Mayela Rojas Castro

Ilustres abogados y amantes de la literatura

Desde lo más hondo a ti clamo, Señor,

desde las profundidades

de mis propios abismos insondables,

desde mis antiguas y desoladas soledades,

a ti clamo:

desde mis angustias

desde las nostalgias que me han taladrado desde las hondas heridas

que aún permanecen abiertas

y en pura carne viva;

desde mi propia existencia

y clavado en cuatro llagas que no sanan,

a ti clamo Señor,

a ti grito y encomiendo mis días

a ti grito y encomiendo mis noches

y te llamo y encomiendo mis pasos.

2

Porque en realidad a veces me siento

completamente solo

con soledad de páramo y desierto desolado.

Soledad de pobre náufrago

en costa remota y solitaria;

a ti clamo ioh Señor!

desde mi propia ceniza miserable

desde mi propio barro de hombre frágil.

3

No me abandones,

no te apartes de mí;

no te apartes de nosotros.

Desde lo más hondo a ti ruego

no nos sentimos resguardados

pues día y noche nos acechan

los que maquinan y urden maldades;

los que espían tras las sombras nuestros pasos;

pues vivimos en valle de sombras de muerte

y somos ovejas trasquiladas

en medio de lobo rapaces;

de lo profundo de mi ser sale mi ruego

a ti clamo, Dios mío ...

Noviembre, 2009

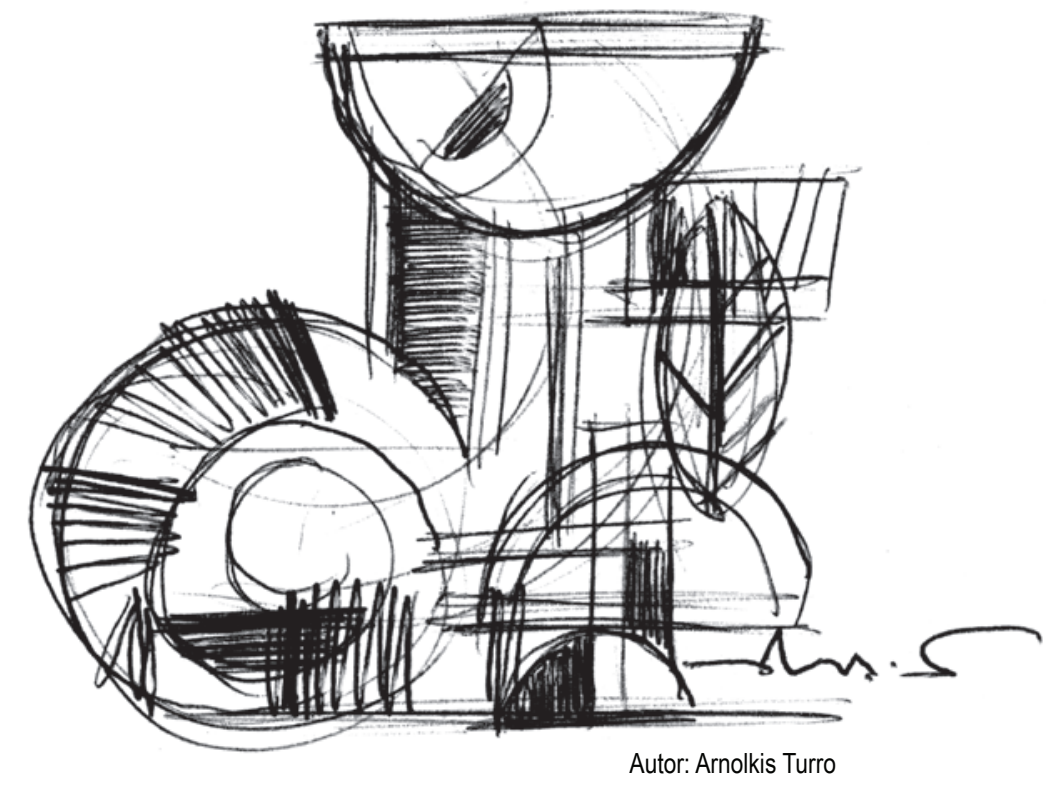

